\author{
Military Technical College \\ Kobry Elkobbah, \\ Cairo, Egypt
}

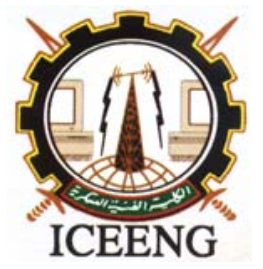

\author{
$5^{\text {th }}$ International Conference \\ on Electrical Engineering \\ ICEENG 2006
}

\title{
RANGE INCREASE OF THE PASSIVE SURVEILLANCE SYSTEM Matousek $^{*}$ Z., Ochodnicky ${ }^{* *}$ J.
}

\begin{abstract}
Passive surveillance system (PSS) is one of the basic equipment in process of the electronic reconnaissance. During the past ten years multilateration PSS have been engaged in air traffic control too. Well-know systems in this field are e.g. TAMARA and VERA-E which are products of the Czech Republic industry. Absence of the signal transmitting and receiving of the signal source only is one of their main advantages. Important parameters of PSS are range and quality of the reconnaissance information. The paper fixates to problems of recent PSS systems range increase independently of signal sources parameters. The possibility of range increasing looks through the receiver bandwidth adaptation. Receiver bandwidth adaptation of the PSS system provides increasing of the receiver sensitivity and result is the increase of the range. Theoretical analysis of the energetic conditions is present and some results of the modeling and simulations shown in paper.
\end{abstract}

\section{KEY WORDS}

Passive Surveillance System, ELINT, Receiver Bandwidth, Range, Bandwidth Adaptation

\section{INTRODUCTION}

Radar is the principle means of detection used in air and ground surveillance platforms but it is being augmented by other systems to provide redundancy and counter the development of radar-evading stealth technology. By providing additional means of locating and identifying contacts, operators have a back-up in case of radar malfunction and the means to confirm the identity of radar contacts. Also there may be tactical reasons for switching off radar emissions to stop an enemy locating or jamming them. So-called passive surveillance means that electronic and signals intelligence (ELINT/ESM, SIGINT) that rely on monitoring of enemy radar and radio communications traffic are attracting a growing amount of interest. During the cold war these systems were used primarily for strategic reconnaissance against the Soviet

\footnotetext{
* Lecturer, Department of Electronics, Armed Forces Academy, Liptovsky Mikulas, Slovakia

** Associate professor, Department of Electronics, Armed Forces Academy, Liptovsky Mikulas, Slovakia
} 
Union but during the past ten years they have been engaged in crisis-management missions to support peacekeeping, enforcement operations and air traffic control [1].

The PSS is a highly advanced sensor that is able to detect aircraft, ships, and ground vehicles from signals emitted by their radar, communications, and other onboard electronic systems. PSS itself emits no signals, and therefore cannot be electronically detected by sensor platforms of opposing forces.

Important parameter of the ELINT/ESM system is the surveillance range (range of reconnaissance). The range of reconnaissance is function of many variables (signal source power, receiver antenna gain, receiver sensitivity etc.). Specific PSS attribute is the receiver bandwidth. Theoretical analysis of energetic conditions show that receiver bandwidth adaptation of the PSS system provides increasing of the receiver sensitivity and result is the increase of the range.

\section{ENERGETIC CONDITIONS ANALYSIS}

The Passive surveillance system designed to air, ground and maritime target detection, tracking and its signal analysis (Fig.1). Result of the signal analysis is target identification (type, model, parameters etc.). The "finger printing" method is well-known.

The PSS usually uses the TDOA (Time Difference of Arrival) method to source localization by three or four stations (positions). TDOA method requires that the source work in pulse mode. The base for energetic analysis of that system is beacon equation [2]:

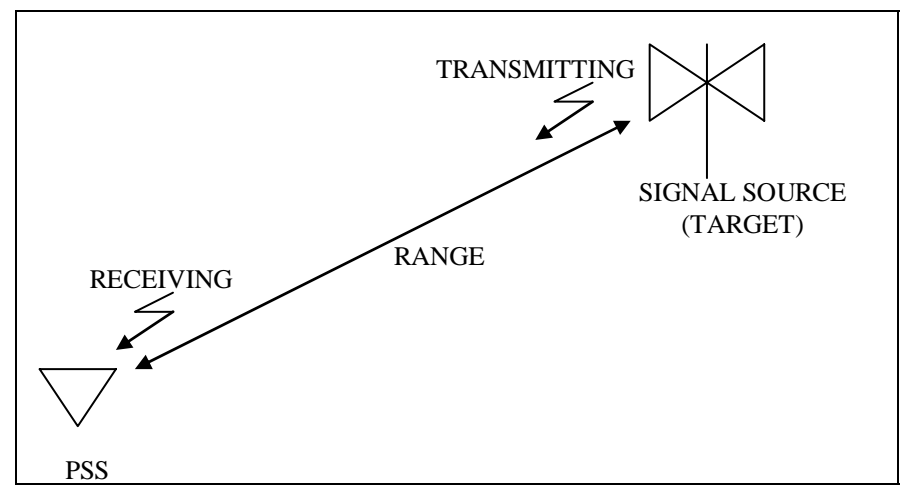

Fig. 1. Basic concept of the passive surveillance system

$$
R=\sqrt{\frac{P_{z} G_{z} G_{p} \lambda^{2}}{(4 \pi)^{2} P_{p} L}}
$$

where $\boldsymbol{R}$ is the distance of source to PSS (range), $\boldsymbol{P}_{\boldsymbol{z}}$ is the source power, $\boldsymbol{G}_{\boldsymbol{z}}$ is the source transmitter antenna gain, $\boldsymbol{G}_{\boldsymbol{p}}$ is the PSS receiver antenna gain, $\lambda$ is the wave length of signal, $\boldsymbol{L}$ presents additional losses in system, and $\boldsymbol{P}_{\boldsymbol{p}}$ is the input power of the received signal.

For graphic presentation of the range in specific configuration of PSS the technical parameter TPS of the system it is necessary formalize [3] that

$$
T P S=\frac{P_{p}}{P_{z} G_{z} G_{p}}=\frac{\lambda^{2}}{(4 \pi)^{2} R^{2} L}
$$


Pulse signal transmitted by source will be detected by PSS in case, if TPS is bigger than the some threshold PU only, according to formula

$$
P U=\frac{P_{p \min }}{P_{z} G_{z} G_{p}}
$$

where $\boldsymbol{P}_{\boldsymbol{p} \text { min }}$ is the receiver sensitivity of the PSS. For the presentation in decibels

$$
\begin{gathered}
T P S_{[d B]}=10 \log T P S \\
P U_{[d B]}=10 \log P U
\end{gathered}
$$

Receiver sensitivity of the PSS represents its technical parameters and conditions of the operation, according to next formula

$$
P_{p \min }=k T_{0} F \frac{S}{N} B
$$

where $\boldsymbol{k}$ is Boltzman's constant $\left[1,38.10^{-23}\right], \boldsymbol{T}_{\boldsymbol{0}}$ is scene temperature $\left[{ }^{\circ} \mathrm{K}\right], \boldsymbol{F}$ is the receiver noise number, $\boldsymbol{S} / \boldsymbol{N}$ is the minimum signal to noise ratio at the receiver input and $\boldsymbol{B}$ is the receiver bandwidth.

Definition of the threshold PU depends on the known technical parameters of recent signal sources and PSS in specific configuration. Generally true values are present in Table 1.

\section{SIMULATION RESULTS}

For modeling, simulation and experimental calculations of the PSS range the MATLAB ver. 6.5 was used [4] and PSS simulation values from the third column of table 1 applied. Values of additional losses was considered at level $L=1,6 \div 2$. Result of this values substitution in equations (3) and (5) is $P U_{[d B]}=-166 \mathrm{~dB}$.

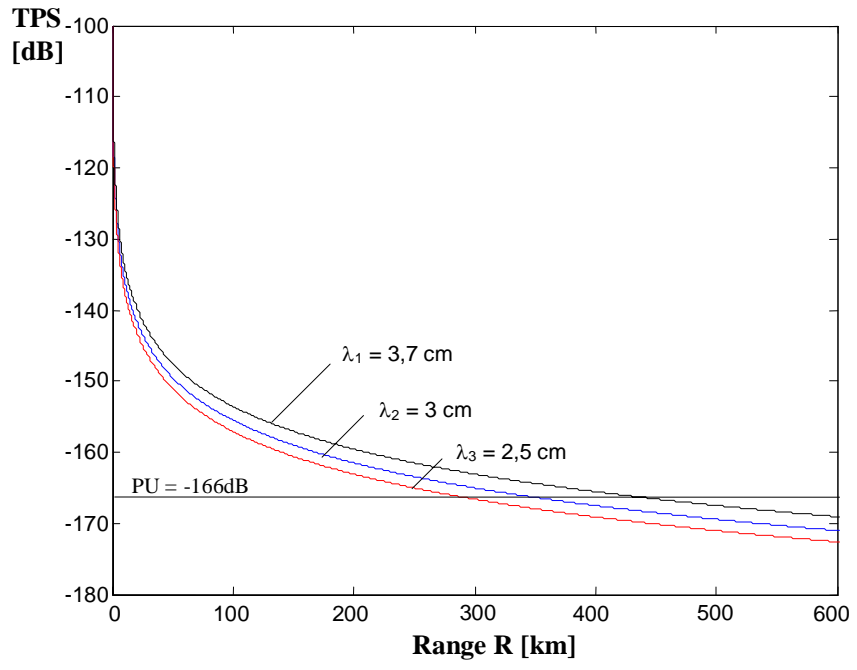

Fig. 2. Range of PSS for different wavelength

Range to pulse sources in present system configuration for different wavelength $\lambda$ is shown in Fig. 2. Because parameters of the PSS are fixed, in case of constant wavelength the range 
increase isn't possible. Result of limiting values of the PSS range is the low detection probability and signal processing and analysis quality.

Table 1. Technical parameters of the recent signal sources and PSS

\begin{tabular}{|c|c|c|}
\hline Parameter & Value range & Simulation value \\
\hline$P_{p \min }[\mathrm{W}]$ & $10^{-11}-10^{-13}$ & $10^{-11}$ \\
\hline$P_{z}[\mathrm{~W}]$ & $500-10^{4}$ & 500 \\
\hline$G_{Z}$ & $100-10^{3}$ & 100 \\
\hline$G_{p}$ & $8-40$ & 8 \\
\hline
\end{tabular}

From above results that value of TPS must be at full far-off PU value. The optimal difference between TPS and PU values is $5 \mathrm{~dB}$ and more [2]. According to the value of this difference the next areas creates - suitable, slow-suitable and non-suitable (Fig. 3).

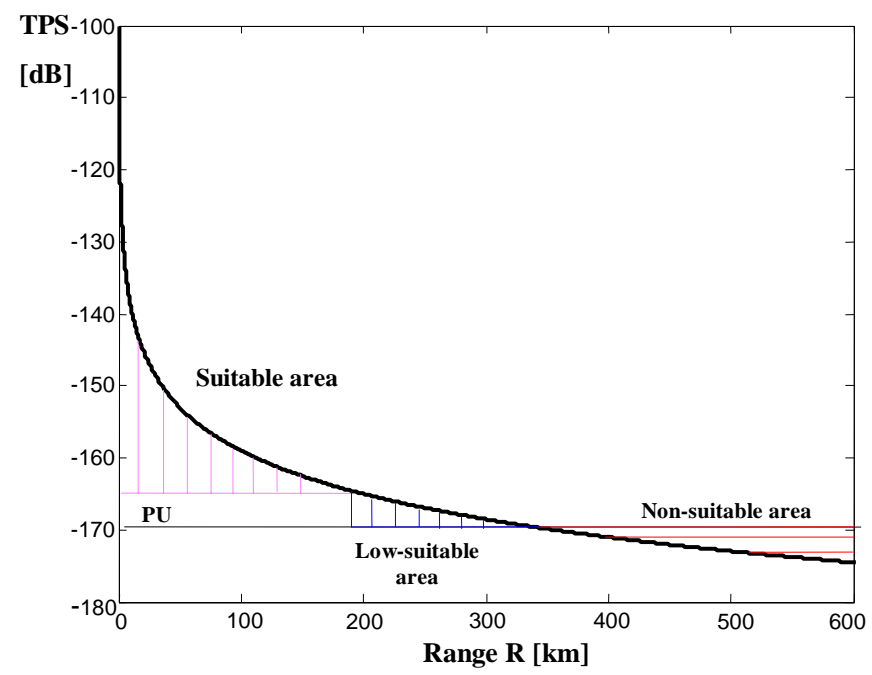

Fig. 3. Classification of TPS-PU difference areas

Values in denominator of (3) are defined by construction of the signal source and PSS. The bandwidth of PSS receiver is defined according to minimum of the processed pulse length $\boldsymbol{t}_{\boldsymbol{i}}$ min under required quality of analysis by

$$
B \geq \frac{1}{t_{i \min }}
$$

For signal processing with longer $\boldsymbol{t}_{\boldsymbol{i}}$ isn't necessary the predefined bandwidth. That fact gives the possibility of sensitivity value reduction. In this case - according to (3), the PU decreases, and the suitable area increases.

The adaptive regulation of bandwidth by pulse length is possible according to [5]

$$
B_{\text {kopt }}=\frac{1,37}{t_{i}}
$$

and results of simulations for source F-15D equipped with radar AN/APG-63 are presented in Figure 4. Adaptive control of the receiver bandwidth is possible in case of detected and identified targets. Result of bandwidth adapting for situation in Fig. 4 is increase of maximum PSS range from $320 \mathrm{~km}$ to $790 \mathrm{~km}$. 


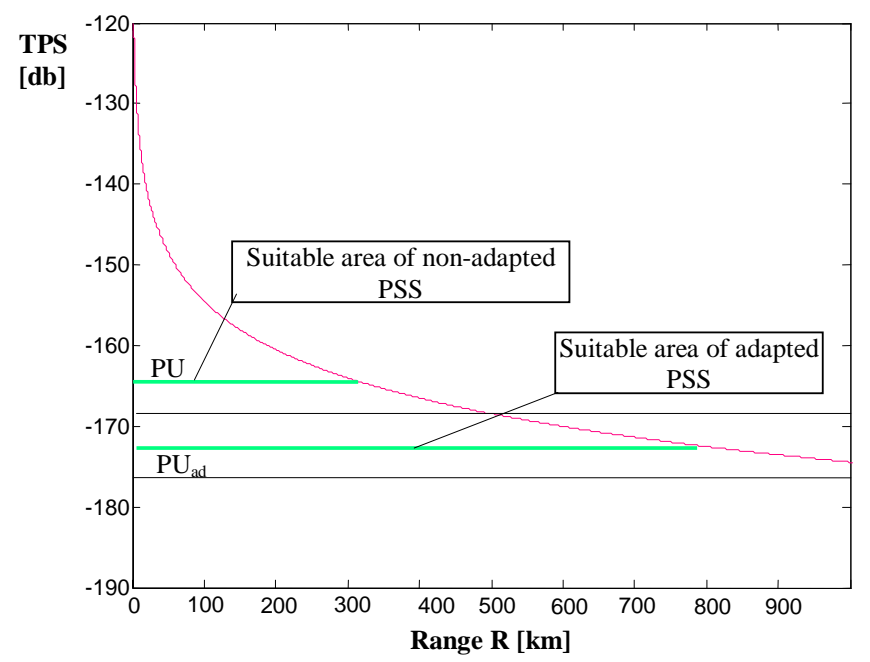

Fig. 4. Difference between the range of adapted and non-adapted PSS

\section{CONCLUSION}

Adaptive control of the PSS receiver bandwidth provides the increase of range to sources. Calculations and simulation results which presented in paper confirm this idea, but there are some restrictions that follow from the maximum range on Earth.

\section{REFERENCES}

[1] Ochodnicky, J., "Passive surveillance systems development”, Proceedings of the conference „Air Defence Systems Trends “, pp 84-92, Military academy, Liptovsky Mikulas, (2001)

[2] Cole, H. W., Understanding Radar, Blackwell Scientific Publications, Oxford, (1992).

[3] Matousek, Z., "Detection of secondary emission energy" Final report of the study PT 9307/5, Military academy, Liptovsky Mikulas, pp 53-64, (1996).

[4] Roberts, M. J., Signals and Systems - Analysis Using Transform Methods and MATLAB, International Edition, (2003)

[5] Toma, E., Optimal receiving of signal in noise background, Military academy, Liptovský Mikuláš, (1978). 